\title{
Lack of Lithium-Like Behavioral and Molecular Effects in IMPA2 Knockout Mice
}

\author{
Kim Cryns*,1,3, Alon Shamir 2,3, Joseph Shapiro', Gie Daneels', Ilse Goris', Hansfried Van Craenendonck', \\ Roel Straetemans', RH Belmaker', Galila Agam², Dieder Moechars' and Thomas Steckler' \\ 'Research and Early Development Europe, Johnson \& Johnson Pharmaceutical Research and Development, Beerse, Belgium; ${ }^{2}$ Stanley Research \\ Center, Faculty of Health Sciences, Ben Gurion University of the Negev and Mental Health Center, Beer-Sheva, Israel
}

\begin{abstract}
Lithium is a potent mood-stabilizing medication in bipolar disorder. Despite 50 years of clinical use, the mechanism of action is unknown. Multiple effects have been attributed to lithium including the uncompetitive inhibition of inositol monophosphatase (IMPase). IMPA2, one of the genes that encode IMPase, is located in a region with linkage to bipolar disorder. Owing to the role of IMPase in cell signaling and the possibility that this enzyme is a target for mood-stabilizing drugs, we generated IMPA2 ${ }^{-1-}$ mice. Possible involvement of IMPase in complex behaviors related to affective disorders was assessed by monitoring the behavior of the IMPA2 ${ }^{-1-}$ mice in the forced swim test, the tail suspension test (TST), the elevated zero-maze and open field test. It has been described that chronically lithium-treated mice exhibit reduced immobility time in the forced swim test and decreased exploratory behavior. We found increased rearing of IMPA2 ${ }^{-1-}$ mice in the open field, suggesting an increased exploratory behavior. Although immobility time of IMPA2 ${ }^{-1-}$ female but not male mice in the forced swim test was reduced, no difference was found between male and female IMPA2 ${ }^{-1-}$ and IMPA2 ${ }^{+/+}$mice in the TST and overall there was no clear effect of the deletion of IMPA2 on depression-like behavior. Frontal cortex IMPase activity and inositol levels in the $1 \mathrm{MPA} 2^{-1-}$ mice did not differ from $I M P A 2^{+/+}$mice, but kidney inositol levels were reduced. In conclusion, phenotypic characterization of the IMPA2 ${ }^{-1-}$ mouse indicates that deleting IMPA2 does not mimic the effects of lithium treatment.

Neuropsychopharmacology (2007) 32, 88 I-89I. doi: I0. I038/sj.npp. I 30I I54; published online I2 July 2006
\end{abstract}

Keywords: IMPA2; lithium; bipolar disorder; behavioral analysis; IMPase activity; inositol levels

\section{INTRODUCTION}

Bipolar disorder is a serious psychiatric disorder. It affects at least $1 \%$ of the population and is characterized by episodes of mania and depression (Goodwin and Jamison, 1990). Notwithstanding the devastating impact, the underlying pathophysiology is still unknown. Lithium has been the standard pharmacological treatment for bipolar disorder over the last 50 years (Goodwin and Jamison, 1990). In vivo and in vitro studies demonstrated that lithium exerts multiple effects on neurotransmitter/receptor-mediated signaling, ion transport, signal transduction cascades, hormonal and circadian regulation, and gene expression (for a review, see Jope (1999) and Quiroz et al (2004)). At

\footnotetext{
*Correspondence: Dr K Cryns, Research and Early Development Europe, Johnson \& Johnson Pharmaceutical Research and Development, Turnhoutseweg 30, B-2340 Beerse, Belgium, Tel: + 3214 603819, Fax: + 32 14 607266, E-mail: kcryns@prdbe.jnj.com

${ }^{3}$ Both authors contributed equally to this work.

Received 28 November 2005; revised 20 April 2006; accepted 6 June 2006

Online publication: 7 June 2006 at http:/www.acnp.org/citations/ Npp060706050702/default.pdf
}

therapeutically relevant concentrations, it inhibits a group of at least four related phosphomonoesterases (inositol monophosphate phosphatase, inositol polyphosphate phosphatase, fructose 1,6-bisphosphate 1-phosphatase, and bisphosphate nucleotidase), the metabolic enzyme phosphoglucomutase, and glycogen synthase kinase-3 (GSK3). Despite 50 years of clinical use and despite intensive research, the precise mechanism by which lithium exerts its therapeutic effects is still unknown. A heuristic hypothesis proposed to explain lithium's mechanism of action is the inositol depletion hypothesis (Berridge et al, 1989), which suggests that uncompetitive inhibition of inositol monophosphatase (IMPase) and inositol polyphosphate 1-phosphatase (IPPase) by therapeutically relevant lithium concentrations leads to an accumulation of inositol phosphates and a corresponding depletion of free myo-inositol. The consequent reduced rate of re-synthesis of phosphoinositide second messenger signal generation attenuates the response to neurotransmission. Valproic acid and carbamazepine, two other mood-stabilizing drugs, also cause depletion of free myo-inositol in rodent brain and in neuronal cells in vitro (Shaltiel et al, 2004; Williams et al, 2002), thereby indicating that alterations in phosphatidylinositol-cycle activity may indeed play an important 
role in the pathophysiology and/or treatment of bipolar disorder.

IMPase is a key enzyme in the phosphatidylinositol signaling system. Two human genes encoding for IMPase (IMPA genes) have been cloned. The IMPA1 gene was found on chromosome 8q21.13-21.3 (Sjoholt et al, 1997) and IMPA2 was located on chromosome 18p11.2 (Sjoholt et al, 2000; Yoshikawa et al, 2000, 1997). Several studies have indicated the presence of a susceptibility locus for bipolar disorder on chromosome 18p (Berrettini et al, 1994; Rojas et al, 2000). Sjoholt et al (2004) reported an association between bipolar illness and single-nucleotide polymorphisms in the promoter of IMPA2. Yoon et al (2001) reported that B lymphoblast cell lines derived from male bipolar patients exhibit downregulation of IMPA2 expression accompanied by high free intracellular $\mathrm{Ca}^{+2}$ concentration.

Subconvulsive doses of the cholinergic agonist pilocarpine induce limbic seizures in rodents pretreated with lithium (Honchar et al, 1983). Lithium by itself does not have proconvulsant effects in rodents. Induction of lithiumpilocarpine seizures results in a drop in cortical inositol and elevation of inositol monophosphate levels. The reversal of lithium's effect by inositol provided behavioral support for the inositol depletion hypothesis (Kofman and Belmaker, 1993).

Owing to the important role of IMPase in cell signaling, in general, and the possibility that this enzyme is a target for mood-stabilizing drugs, we used a retrovirus-mediated gene trap strategy to generate $I M P A 2^{-/-}$mice. The present study describes molecular, biochemical, behavioral, and pharmacologic findings in IMPA2 $2^{-1-}$ mice.

\section{MATERIALS AND METHODS}

\section{Generation of $I M P A 2^{-/-}$Mouse}

The IMPA2 $2^{-1-}$ mouse was generated by Lexicon Genetics Incorporated (The Woodlands, TX) using a gene trapping method. This approach disrupts gene function through the introduction of heterologous splice acceptor and splice donor sites that disrupt normal splicing of the trapped gene (Zambrowicz and Friedrich, 1998). The gene trap integration site is determined by $3^{\prime}$ rapid amplification of cDNA ends (RACE) followed by sequencing analysis. Today sequences of over 270000 gene-trapped ES cell clones have been deposited into a searchable database (http://www. lexicongenetics.com/omnibank/overview.php). By searching the Lexicon Genetics database, we identified an 129Sv/Evbrd ES cell clone (Omnibank number OST 203987) containing a gene trap insertion, which is located in the first intron of the IMPA2 gene (Figure 1). $129 \mathrm{~Sv} /$ Evbrd ES cell clones containing this insertion were injected into blastocysts to produce chimeric mice that were bred to C57BL/6J mice (1 generation) for germline transmission of the targeted allele. The resulting heterozygous animals were subsequently crossed to generate all three genotypes. Background effects were minimized by using mice with the same variation in genetic background. PCR was used to screen genotypes from DNA isolated from mouse tail biopsy samples. Primers 5 'CTACAGCGGGAGGAGGTTTGCATGG$3^{\prime}$ and $5^{\prime}$-TTCCTCCTAACTCGGGTCTGTGC- $3^{\prime}$ amplified a $376 \mathrm{bp}$ band from the wild-type allele, whereas primers

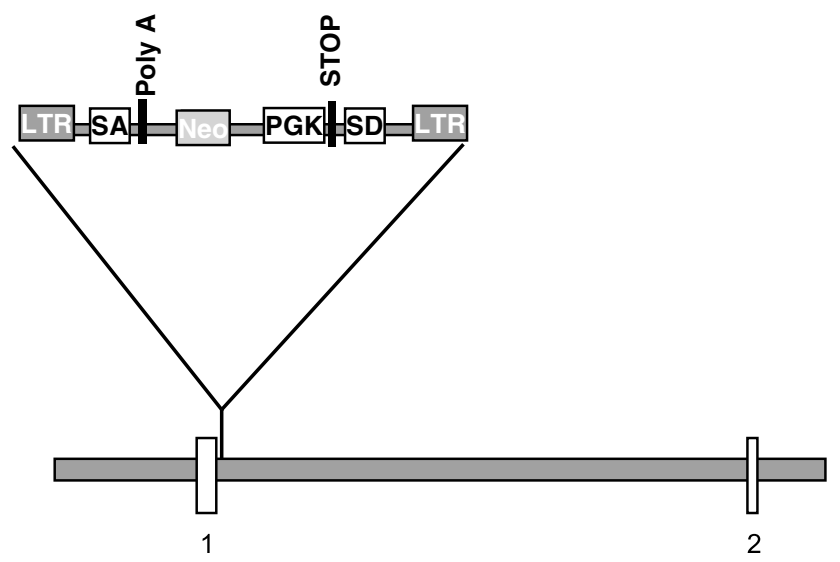

Figure I Generation of the IMPA2 $2^{-1-}$ mouse. IMPA2 $2^{-1-}$ mouse was generated using a retrovirus-mediated gene trap that occurred immediately downstream of exon I of the IMPA2 gene and introduced a stop codon. White boxes indicate exons.

$5^{\prime}$ AAATGGCGTTACTTAAGCTAGCTTGC- $3^{\prime}$ and $5^{\prime}$-TTCC TCCTAACTCGGGTCTGTGC- $3^{\prime}$ amplified a 228 bp band from the knockout allele.

\section{Measurement of Gene Expression}

To assess the effect of the trapping event, IMPA2 and IMPA1 expression was investigated using quantitative RTPCR in several tissues of IMPA2 ${ }^{+/+}, I M P A 2^{+/-}$, and $I M P A 2^{-/-}$mice. Total RNA was isolated from different tissues using Trizol (Invitrogen; Carlsbad, CA) and firststrand cDNA synthesis was performed on $0.5 \mu \mathrm{g}$ total RNA using random hexamer primers and SuperscriptII RT (Invitrogen; Carlsbad, CA). Quantitative PCR was performed on a ABIPrism 7700 cycler (Applied Biosystems; Foster City, CA) using a Taqman PCR kit. Serial dilutions of cDNA were used to generate standard curves of threshold cycles $v s$ the logarithms of concentration for $\beta$-actin and IMPA2 and IMPA1. A linear regression line calculated from the standard curves allowed the determination of transcript levels in RNA samples from the mice. Specific sets of primer-probe pairs were used to assay expression levels (Table 1).

\section{IMPase Activity}

IMPase activity was measured in tissue from 17- to 19week-old $I M P A 2^{+/+}, I M P A 2^{+/-}$, and IMPA2 ${ }^{-/-}$male mice ( $n=10$ per genotype). Tissue was divided in two. One half was used to measure IMPase activity; the other half was used to determine inositol levels. Hippocampus, frontal cortex, and kidney specimens were diluted (1 mg tissue/ $81 \mu \mathrm{l}$ homogenization buffer $(50 \mathrm{mM}$ Tris- $\mathrm{HCl} \mathrm{pH} \mathrm{8.5,}$ $150 \mathrm{mM} \mathrm{KCl}, 0.5 \mathrm{mM}$ EDTA, and $0.1 \mathrm{mM}$ EGTA)). Tissue samples were sonicated for $10 \mathrm{~s}, 4^{\circ} \mathrm{C}$ at $50 \%$ power capacity (Heat System Ultasonic Inc.). The reaction mixture (final volume $105 \mu \mathrm{l})$ contained the following components: $40 \mu \mathrm{l}$ homogenization buffer, $45 \mu \mathrm{l}$ reaction buffer $(50 \mathrm{mM}$ Tris$\mathrm{HCl} \mathrm{pH} 7.8,250 \mathrm{mM} \mathrm{KCl}$, and $3 \mathrm{mM} \mathrm{MgCl} 2$ ), $5 \mu \mathrm{l}$ inositol-1phosphate $0.7 \mathrm{mM}$, and $5 \mu \mathrm{l}$ crude homogenate. Each experiment included a standard curve of Pi (0-6 nmol). In 
Table I Primer and Probes that were Used to Assay Expression Levels

\begin{tabular}{|c|c|c|c|}
\hline Gene & Forward primer & Reverse primer & Probe \\
\hline IMPAI & 5'AGCTGTTTCAATTGGCTTCCTT3' & 5'GCCGGTGTACATCTTATCTTCCA3' & 5'TGAATAAAGAGATGGAGTTTGGATTGTGTACAGCT3' \\
\hline IMPA2 & 5'GAGGTGGCCGTGCAGTTG3' & 5'AGACGCGTIITTCCTCTGTCA3' & 5'CCTGATGATTTGTCCCGCACGCA3' \\
\hline$\beta$-Actin & 5'CATCTTGGCCTCACTGTCCAC3' & 5'GGGCCGGACTCATCGTACT3' & 5' TGCTTGCTGATCCACATCTGCTGGA3' \\
\hline
\end{tabular}

order to distinguish IMPase activity from nonspecific phosphatases, the reaction was carried out in the presence and absence of $30 \mathrm{mM}$ lithium chloride $(\mathrm{LiCl}) . \mathrm{LiCl}$ is a specific inhibitor of this enzyme (Atack et al, 1995) and at these concentrations totally inhibits IMPase activity. Incubation was carried out for $30 \mathrm{~min}$ at $37^{\circ} \mathrm{C}$. The reaction was stopped by mixing with $100 \mu \mathrm{l}$ color reagent. The color reagent was prepared by mixing $5 \mathrm{ml} 4.2 \%$ ammonium molybdate (prepared in $5 \mathrm{~N} \mathrm{HCl}$ ) and $15 \mathrm{ml} 0.2 \%$ Malachite Green (Sigma, St Louis, MO) in water. On the day of use, $0.1 \%$ Tween 20 was added. The color reagent was allowed to stand at room temperature for $15 \mathrm{~min}$ before use. Inorganic phosphate liberated from inositol-1-phosphate was quantified spectrophotometrically in an ELISA reader (iEMS, Labsystems) at $620 \mathrm{~nm}$. The enzyme activity was calculated as the difference between the values in absence minus the activity in the presence of LiCl. Enzyme activity was calculated per $\mathrm{mg}$ protein assayed by the Bradford assay (Bio-Rad). The amount of crude homogenate used in the assay and the incubation time were in the linear range for this reaction. The activity in each specimen was measured in two separate experimental days, each time in triplicate. The assays were carried out in a blind and balanced manner (each run included similar number of specimens from IMPA $2^{+/+}$, IMPA2 $2^{+/-}$, and IMPA2 $2^{-/-}$mice).

\section{Gas Chromatographic Measurement of Inositol Levels}

Mouse hippocampus, frontal cortex, and kidney specimens free inositol levels were analyzed as trimethylsilyl derivatives by gas chromatography, as previously described (Shapiro et al, 2000) with minor modification. Samples of tissue were extracted in $0.5 \mathrm{ml}$ of boiling water containing $400 \mu \mathrm{g}$ mannitol for $5 \mathrm{~min}$, the denatured tissue was centrifuged $\left(1000 \mathrm{~g}, 10 \mathrm{~min}, 4^{\circ} \mathrm{C}\right)$, and $250 \mu \mathrm{l}$ supernatant were lyophilized ( $3 \mathrm{~h}$, Speed Vac SC 110); silylation of the dried sample was carried out with $200 \mu \mathrm{l}$ of a mixture of pyridine: bis-(trimethylsilyl)-trifluoroacetamide:chlorotrimethylsilan 10:2:1 (vol/vol/vol) for $24 \mathrm{~h}$ at room temperature. In total, $1 \mu \mathrm{l}$ of aliquots was chromatographed on a capillary column (RTX-1, $15 \mathrm{~m}, 0,25 \mathrm{~mm}$ ID, Restek), using a Chrompack gas chromatograph with a hydrogen flame ionization detector. The oven temperature was $150-220^{\circ} \mathrm{C}$ with rise of $10 \% \mathrm{~min}$ and the carrier gas was nitrogen with a flow of $30 \mathrm{ml} / \mathrm{min}$. The TMS derivatives of mannopyranoside and myo-inositol had retention times of 3.5 and $6.3 \mathrm{~min}$, respectively. Under these conditions, quantitation was performed with the use of TMS derivatives of standard myo-inositol under the same conditions and with mannopyranoside as an internal standard. The correlation coefficient of the daily standard curves was always above 0.987 . We have previously tested replicate reliability in rat brain. When two different brain specimens from four rats were sampled, the correlation coefficient for myo-inositol was 0.8 . When a single brain extract was divided into 10 separate samples, each assayed individually, the coefficient of variation was $23.5 \%$. The assays were carried out in a blind and balanced manner (each run included similar number of specimens from IMPA2 $2^{+/+}$, IMPA2 ${ }^{+/-}$, and $I M P A 2^{-/-}$mice). The results are means of at least two aliquots from each sample.

\section{Animals}

Animals that were used for behavioral analysis, measurement of adrenocorticotrophic hormone and corticosterone levels, and pharmacologic studies were individually housed and kept under 12:12 h light/dark cycle (lights on at 0600 hours) in a temperature- and humidity-controlled room with food and water ad libitum. For the behavioral analysis, the same mice were tested in the different paradigms in the following order: open field test, elevated zero-maze, tail suspension test (TST), and forced swim test. For the measurement of stress hormones and for the different pharmacologic studies (amphetamine-induced locomotor activity, pilocarpine-induced seizures, $\mathrm{LD}_{50}$ of lithium, and chronic lithium treatment), the mice were only used once. All experiments were conducted in an illuminated room during the light phase of the light/dark cycle. Experiments were approved by the animal care and use committee of Johnson \& Johnson Pharmaceutical Research and Development.

\section{Behavioral Analysis}

A panel of 39 male mice (19 IMPA2 $2^{+/+}$and 20 IMPA2 $2^{-/-}$ mice) and 31 female mice (16 IMPA2 $2^{+/+}$and 15 IMPA2 $2^{-/-}$ mice) with age ranging from 14 to 21 weeks was used to assess anxiety-related behavior in the open field test and elevated zero-maze, and depression-related behavior in the TST and forced swim test. Experiments were conducted in the order described above with at least 1 week in-between experiments. Male and female animals were tested on different days to avoid confounding factors by pheromones.

Open field test. Locomotor activity was monitored using a Tru-scan ${ }^{C}$ system (Coulbourn instruments, Allentown, USA). The animal was placed in the center of the activityfield arena, which is a transparent Perspex cage $(W \times D \times H$; $260 \times 260 \times 400 \mathrm{~mm}$ ) equipped with two photo-beam sensor rings to register horizontal and vertical activity. Testing lasted $30 \mathrm{~min}$ and distance traveled was measured in 5-min time-bins. The relative time spent in the 'center' (=total time spent in the center/total time in task, in \%) and 'relative distance traveled in the center of the open field' (= total distance traveled in the center of the open 
field/total distance traveled, in \%) were analyzed as a measure for anxiety-like behavior.

Elevated zero-maze. The zero-maze consisted of an annular runway (diameter: $50 \mathrm{~cm}$, width: $5 \mathrm{~cm}$ ), elevated $50 \mathrm{~cm}$ above the floor. The maze was divided in four parts, that is, two opposite open parts and two opposite closed parts. The sidewalls of the opposing closed parts had a height of $20 \mathrm{~cm}$; the open parts had borders with a height of $3 \mathrm{~mm}$. The maze was enclosed by a black cabinet (size: $150 \mathrm{~cm}$ high by $132 \mathrm{~cm}$ wide). Light intensity on the open arms was 10 Lux and on the closed arms 2 Lux. All the animals were placed in the same start position, just in front of the opening of the closed part, facing the closed part. The animals were allowed to freely explore the maze for $5 \mathrm{~min}$ and their behavior was recorded and analyzed using the Ethovision Pro video tracking system (Noldus, The Netherlands). The software was capable of measuring the distance traveled and the time spent in each part of the maze. Three $I M P A 2^{+/+}$and $1 I M P A 2^{-1-}$ male mice were excluded from the analysis because they fell off the maze during testing.

TST. Mice were suspended by their tail to a hook in a test chamber using adhesive tape. Total duration of immobility was measured over a period of 6 min using the Videotrack system (Viewpoint, France). The Videotrack system was validated in-house with standard antidepressant compounds. For both mouse panels, one IMPA2 $2^{+/+}$and two $I M P A 2^{-/-}$mice were excluded for analysis because the mice curled up towards their tail or fell off during testing.

Forced swim test. Mice were placed in a cylinder (diameter $10 \mathrm{~cm}$ ), filled with water to a height of $10 \mathrm{~cm}$ (such that the mouse could not touch the bottom or rim of the cylinder at any point) and a temperature of $25 \pm 1^{\circ} \mathrm{C}$. Each mouse was pre-exposed to swim-stress for $6 \mathrm{~min}$ on day 1 and a test session of $6 \mathrm{~min}$ was performed $24 \mathrm{~h}$ later. Total duration of immobility was measured using the Videotrack system (Viewpoint, France). The Videotrack system was validated in-house with standard antidepressant compounds.

\section{Measurement of ACTH and CORT after Forced Swim Testing}

Plasma adrenocorticotrophic hormone (ACTH) and corticosterone (CORT) levels were measured in 21- to 32-weekold male and female mice $\left(n=6\right.$ for both female IMPA2 ${ }^{+/+}$ and IMPA2 $2^{-/-}$mice, $n=9$ and 7 for male IMPA2 $2^{+/+}$and $I M P A 2^{-1-}$ mice, respectively). Animals were brought under light ether anesthesia and trunk blood was collected in EDTA blood collection tubes (Microtainer EDTA, Becton Dickinson, Switserland). All tubes were kept on ice and then centrifuged at $1090 \mathrm{~g}$ for $5 \mathrm{~min}$ at $4^{\circ} \mathrm{C}$. Separated plasma was frozen at $-70^{\circ} \mathrm{C}$ for subsequent ACTH or CORT determination (both in duplicate) using the RSL ${ }^{125} \mathrm{I}$ ACTH radioimmunoassay (RIA) kit and ImmuChem ${ }^{\mathrm{TM}}$ double antibody CORT ${ }^{125}$ I kit from MP Biomedicals (USA) following the manufacturer's protocol. ACTH and CORT levels were expressed in $\mathrm{pg} / \mathrm{ml}$ and $\mathrm{ng} / \mathrm{ml}$ plasma, respectively. In a subsequent experiment, ACTH and CORT levels were measured in 10 - to 18 -week-old IMPA2 $2^{+/+}$and IMPA2 $2^{-/}$ female littermates after forced swim testing $(n=12$ and 11 for $I M P A 2^{+/+}$and IMPA2 ${ }^{-/-}$, respectively). Mice were subjected to forced swim testing once only for a total duration of $6 \mathrm{~min}$. At $10 \mathrm{~min}$ after the forced swim test, animals were brought under light ether anesthesia and trunk blood was collected in EDTA blood collection tubes (Microtainer EDTA, Becton Dickinson, Switserland). ACTH and CORT levels were measured as described above.

\section{Pharmacologic Studies}

Amphetamine-induced locomotor activity. The effect of $d$ amphetamine on locomotor behavior was evaluated in $I M P A 2^{+1+}, I M P A 2^{+/-}$, and IMPA2 $2^{-1-}$ male littermates with age ranging from 15 to 32 weeks. $d$-Amphetamine was dissolved in saline. Locomotion was evaluated in the Truscan $^{(}$system (Coulbourn instruments, Allentown, USA). Mice were initially placed into the activity monitor chamber for $1 \mathrm{~h}$, then injected i.p. with vehicle $(10 \mathrm{ml} / \mathrm{kg}$ of body weight; $n=9,10,7$ for IMPA2 ${ }^{+/+}, I M P A 2^{+/-}$, and IMPA2 ${ }^{-/-}$, respectively) or $d$-amphetamine $(1 \mathrm{mg} / \mathrm{kg}, n=8,9,10$ for $I M P A 2^{+/+}, I M P A 2^{+-}$, and IMPA2 $2^{-/-}$, respectively, or $2 \mathrm{mg} / \mathrm{kg}, \quad n=10,10,9$ for IMPA2 $2^{+/+}, I M P A 2^{+/-}$, and $I M P A 2^{-\prime-}$, respectively). After the injection, the animals were returned to the activity-field arena and monitored for $2 \mathrm{~h}$ (in 5-min time-bins).

Pilocarpine-induced seizures. IMPA2 $2^{+/+}$and IMPA2 $2^{-/-}$ male littermates (18-22 weeks old) were injected subcutaneously (s.c) with 100 or $200 \mathrm{mg} / \mathrm{kg}$ pilocarpine $(n=5$ for each dose) and rated for signs of seizures once every $5 \mathrm{~min}$ for $2 \mathrm{~h}$ according to a modified version of the scale used by Patel et al (1988). The scoring was as follows: $0=$ no response; $1=$ gustatory movements and/or fictive scratching; $2=$ tremor; $3=$ head bobbing; $4=$ forelimb clonus; $5=$ rearing, clonus and falling. In addition, the latency to attain rearing, clonus, and falling (a score of 5) was recorded for each mouse (Kofman et al, 1993). A welltrained blind observer scored the mice. To further study the possibility of lithium augmentation to reveal pilocarpine sensitivity of the IMPA2 ${ }^{-9-}$ mice, we pretreated IMPA2 ${ }^{+/+}$ and IMPA2 $2^{-1-}$ male littermates with $3 \mathrm{meq} / \mathrm{kg}(n=5)$ and $6 \mathrm{meq} / \mathrm{kg}(n=5)$ lithium.

$L D_{50}$ of lithium. Isotonic lithium $(20 \mathrm{meq} / \mathrm{kg})$ was injected (i.p.) in 5- to 7-month-old IMPA2 ${ }^{+/+}(n=19)$ and IMPA2 $2^{-/-}$ $(n=17)$ female littermates. The dose was chosen based on Bersudsky et al (1993). Lethality was monitored $24 \mathrm{~h}$ and 5 days after the injection.

Chronic lithium treatment. Adult IMPA2 ${ }^{+/+}, I M P A 2^{+/-}$, and IMPA2 $2^{-1-}$ male littermates (4-10 months old) were treated with control chow $\left(n=12\right.$ for IMPA2 $2^{+/+}$and $I M P A 2^{+/-}, n=10$ for IMPA2 ${ }^{-/-}$) or chow containing $0.2 \%$ ( $n=12$ for every genotype) or $0.4 \%$ lithium carbonate (Teklad, Madison, WI) $\left(n=20\right.$ for IMPA2 $2^{+1+}$ and IMPA2 ${ }^{+/-}$, $n=18$ for IMPA2 ${ }^{-1-}$ ) for 14 days. Water was available ad libitum. Three IMPA2 $2^{+/}$, three IMPA2 ${ }^{+/-}$, and one $I M P A 2^{-/-}$in the $0.4 \%$ lithium carbonate group died during the treatment period. After 14 days, forced swim testing was performed. Data obtained from a satellite experiment demonstrated that chronic treatment of mice with a mixed 
C57BL/6J-129Sv/Evbrd genetic background resulted in average plasma lithium levels of $0.67 \mathrm{mM} \pm 0.069$ (mean \pm SEM) for the $0.2 \%$ group and $2.8 \pm 0.437$ in the $0.4 \%$ group. Sodium plasma levels were comparable between all groups (means in $\mathrm{mM} \pm$ SEM: $105.4 \pm 0.73$, $105.6 \pm 0.78,106.6 \pm 2.16$ for the $0,0.2$, and $0.4 \%$ lithium groups, respectively).

\section{Statistical Analysis}

The Kolmogorov-Smirnov test was used to evaluate the normality assumption of expression data, behavioral data, and CORT and ACTH data after forced swim stress. Expression data, behavioral data, and CORT and ACTH data after forced swim stress were analyzed using a Student's $t$-test or a Mann-Whitney Rank Sum Test in case of data that were not normally distributed. A one-way ANOVA was used to compare IMPase activity and inositol levels between the different genotypes. Parametric statistical analysis was chosen based on our previous data of these assays (Motulsky, 1995).

To evaluate rearing before amphetamine administration, a one-way ANOVA was used. A two-way ANOVA (genotype $\times$ treatment) was used to assess the effect of amphetamine treatment on locomotor behavior and rearing in the open field test and of lithium on immobility in the forced swim test. A two-way ANOVA (gender $\times$ genotype) was also used to analyze CORT and ACTH data in baseline conditions. Residual plots were used to diagnose the appropriateness of the final ANOVA models used. This graphical examination included histograms, QQ-plots, and plots of residuals $v s$ fitted values. No departures from the ANOVA assumptions were detected. In case data were not normally distributed, a $\log _{e}$ transformation was performed. A Fisher's exact test was used to evaluate the effect of acute lithium treatment.

\section{RESULTS}

\section{IMPA2 and IMPA1 Expression}

IMPA2 expression was found to be completely abolished in $I M P A 2^{-I-}$ mice, indicating that the trapping event resulted in a null allele of IMPA2 (Figure 2).

To look for potential compensatory mechanisms, IMPA1 mRNA levels were analyzed in brain and liver tissue from
IMPA2 $2^{+/}(n=8)$ and IMPA2 $2^{-/-}(n=8)$ mice by quantitative RT-PCR. No significant difference could be detected between IMPA2 $2^{+/+}$and IMPA2 $2^{-/-}$mice (brain (mean in arbitrary units $\pm S E M): 1.8 \pm 0.2$ and $2.4 \pm 0.7$ for $I M P A 2^{+/+}$ and $I M P A 2^{-/-}$, respectively, Mann-Whitney $U$-test, $U=63$, $p=0.645$; liver (mean \pm SEM): $2.0 \pm 0.2$ and $2.3 \pm 0.3$ for $I M P A 2^{+/+}$and IMPA $2^{-/-}$, respectively, Student's $t$-test, $t=-0.764, p=0.458)$.

\section{IMPase Activity and Inositol Levels}

IMPase activity and inositol levels were measured in the frontal cortex and in the hippocampus of $I M P A 2^{+/+}$, $I M P A 2^{+/-}$, and IMPA2 $2^{-/-}$mice. As summarized in Table 2, hippocampal IMPase activity was significantly increased by $24 \%$ in the IMPA2 $2^{-/-}$mice (ANOVA: $\mathrm{F}_{(2,27)}=3.39, p=0.05$ ) but no difference was observed in the frontal cortex (ANOVA: $\left.\mathrm{F}_{(2,27)}=1.08, p=0.35\right)$. No difference was observed in inositol levels among IMPA2 $2^{-/-}, I M P A 2^{+/-}$, or IMPA2 $2^{+/+}$mice in the hippocampus (ANOVA: $\mathrm{F}_{(2,26)}=0.677, p=0.51$ ) or in the frontal cortex (ANOVA: $\left.\mathrm{F}_{(2,26)}=2.26, p=0.12\right)$.

Inositol levels and IMPase activity were also compared in the kidneys, which is the tissue with the highest expression of IMPA2 (Figure 2). Reduced IMPA2 gene-dose resulted in a significant reduction in inositol levels $\left(23 \%\right.$ in $I M P A 2^{+/-}$ and $32 \%$ in IMPA2 $2^{-1-}$ mice compared with $I M P A 2^{+/+}$

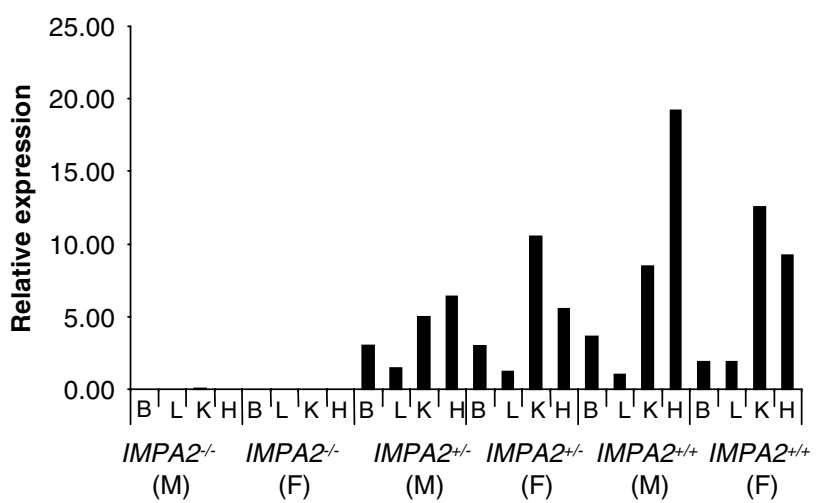

Figure 2 IMPA2 expression is completely abolished in IMPA2 ${ }^{-/-}$mice. B: Brain, H: Heart, K: Kidney, L: Liver. Results are means \pm SEM.

Table 2 Inositol and IMPAse Levels

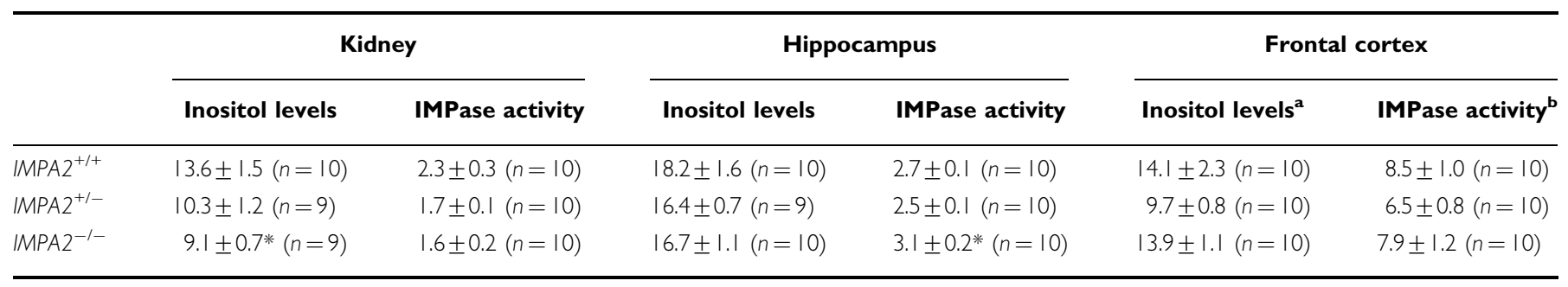


mice), which reached statistical significance (ANOVA: $\left.\mathrm{F}_{(2,25)}=2.25, p=0.03\right)$ but no difference in IMPase activity was found among the three genotype groups (ANOVA: $\mathrm{F}_{(2,27)}=2.19, p=0.13$; Table 2).

\section{Behavioral Analysis}

Table $3 a$ and $b$ summarize the behavioral data for male and female IMPA2 KO mice, respectively. General locomotor and exploratory behavior was assessed in the open field. The distance traveled and the total time in motion was comparable between IMPA $2^{-1-}$ male mice and control mice. In contrast, in female IMPA2 $2^{-1-}$ mice, the distance traveled and the total time in motion was significantly higher compared to IMPA2 $2^{+/+}$female mice. Both in male and female mice, there was no difference between genotypes in the relative distance traveled in the center. However, the relative time spent in the center of the open field was

Table 3 (a) Performance of Male IMPA2 KO Mice in the Open Field, Elevated Zero Maze, Tail Suspension, and Forced Swim Tests; (b) Performance of Female IMPA2 KO Mice in the Open Field, Elevated Zero Maze, Tail Suspension, and Forced Swim Tests

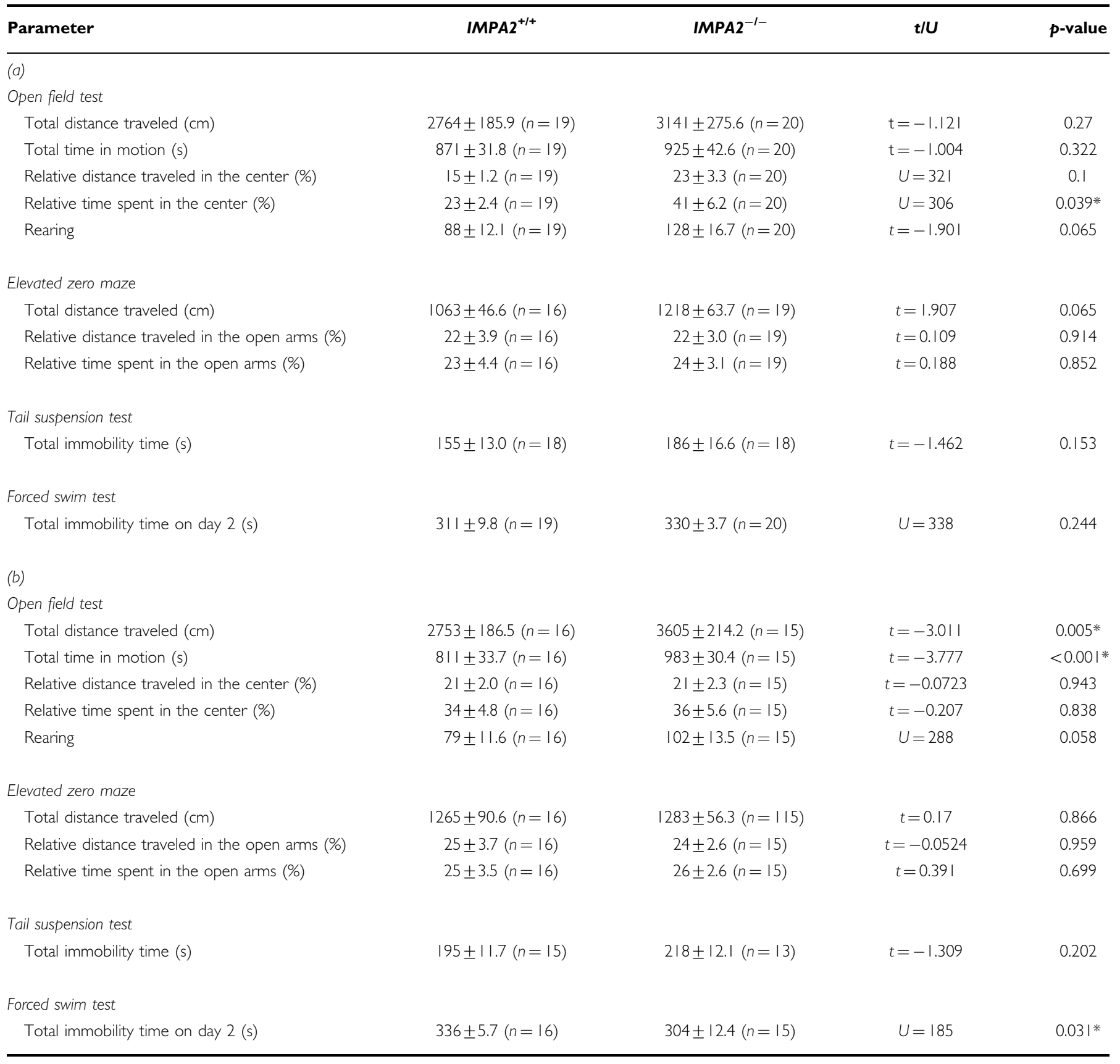

Results are represented as means \pm SEM.

$t=$ Student's $t$-test for parametric data.

$U=$ Mann-Whitney test for nonparametric data.

Asterisk indicates significant difference between $\mathrm{IMPA}^{+/+}$and $I \mathrm{MPA} 2^{-/-}$mice. 
significantly higher in male IMPA2 $2^{-/-}$mice but not in female $I M P A 2^{-1-}$ mice. In addition, a borderline significantly increased number of rearings was observed in both male and female IMPA2 $2^{-1-}$ mice.

In the elevated zero-maze, anxiety-related behavior was evaluated by measuring the relative time spent and distance traveled in the open areas. Measures were not altered in male and female IMPA2 ${ }^{-1-}$ mice. Similarly, analysis of locomotion on the elevated zero-maze revealed no differences between the two genotypes tested in male and female IMPA2 $2^{-1-}$ mice.

Depression-related behavior was assessed in the tail suspension and in the forced swim test. As summarized in Table 3a, male IMPA2 $2^{-1-}$ mice did not exhibit a difference in total immobility time in the tail suspension test or in the forced swimming test. Female IMPA $2^{-/-}$mice also did not exhibit a difference in total immobility time in the tail suspension test but in the forced swim test total immobility time was significantly lower compared to control mice.

\section{Measurement of Plasma ACTH and CORT after Forced Swimming}

ACTH and CORT levels are presented in Table 4. At baseline condition, no genotype effect was seen on ACTH $\left(\mathrm{F}_{(1,24)}=2.69, p=0.11\right)$ and CORT levels $\left(\mathrm{F}_{(1,24)}=0.45\right.$, $p=0.51)$. There was a significant difference in ACTH levels between male and female mice $\left(\mathrm{F}_{(1,24)}=29.92, p<0.0001\right)$ while CORT levels were not different between both genders $\left(\mathrm{F}_{(1,24)}=2.16, p=0.16\right)$. There was no significant genotype $\times$ gender interaction $\left(\mathrm{F}_{(1,24)}=0.09, p=0.77\right.$ and $\mathrm{F}_{(1,24)}=0.01, p=0.93$ for, respectively, ACTH and CORT).

In a subsequent experiment, ACTH and CORT levels were measured in female IMPA2 ${ }^{+/+}$and IMPA2 $2^{-1-}$ mice after forced swim stress. No difference in the magnitude of ACTH (Student's t-test, $t=-1.643, p=0.115$ ) and CORT (MannWhitney $U$-test, $U=144, p=0.479$ ) response was observed between $I M P A 2^{+/+}$and IMPA2 $2^{-/-}$mice.

\section{Pharmacologic Studies}

Amphetamine-induced locomotor activity. Locomotor behavior of $I M P A 2^{+/+}, I M P A 2^{+/-}$, and IMPA2 $2^{-/-}$mice in the open field test was evaluated after $d$-amphetamine administration. Before drug administration, a significant genotype effect on the number of rears was seen
$\left(\mathrm{F}_{(2,85)}=3.92, p=0.0235\right.$, Figure 3a). Post hoc testing indicated rearing was significantly increased in IMPA2 ${ }^{--}$animals compared to IMPA2 ${ }^{+/-}$mice $(p=0.04)$. A tendency for an increase in rearings was seen in IMPA2 ${ }^{-1-}$ compared to $I M P A 2^{+/+}$mice $(p=0.062)$. Baseline locomotor activity as measured by total distance traveled before drug administration was not different between the three genotypes $\left(\mathrm{F}_{(2,84)}=2.209, p=0.116\right.$, Figure $\left.3 \mathrm{~b}\right)$. Amphetamine administration produced a significant increase in total distance traveled (drug effect, $\mathrm{F}_{(2,73)}=49.65, p<0.0001$, Figure $3 \mathrm{c}$ ), but no effect of genotype was observed $\left(\mathrm{F}_{(2,73)}=1.53\right.$, $p<0.223)$. Post hoc analysis indicated that animals treated with 1 and $2 \mathrm{mg} / \mathrm{kg}$ travelled significantly more than control treated animals $(p<0.0001$ for both doses). There was no genotype $\times$ drug interaction $\left(\mathrm{F}_{(4,73)}=0.28, p=0.889\right)$. Detailed analysis of locomotor activity over time confirmed the absence of a genotype and genotype $\times$ drug interaction effect on the total distance traveled (data not shown). Amphetamine treatment resulted in a significant increase in the number of rears $\left(\mathrm{F}_{(2,73)}=9.79, p=0.0002\right)$. Post hoc analysis indicated rearing was increased in animals treated with $1 \mathrm{mg} / \mathrm{kg}(p=0.014)$ and $2 \mathrm{mg} / \mathrm{kg}(p<0.0001)$ compared to saline-treated animals. Treatment with $2 \mathrm{mg} / \mathrm{kg}$ amphetamine also resulted in a significant increase in rearing compared to animals treated with $1 \mathrm{mg} / \mathrm{kg}$ $(p=0.02)$. No genotype effect $\left(\mathrm{F}_{(2,73)}=0.19, p=0.83\right)$ or a genotype $\times$ treatment interaction $\left(\mathrm{F}_{(4,73)}=0.38, p=0.819\right)$ was observed.

Pilocarpine sensitivity. No limbic seizures were observed in $I M P A 2^{+/+}$and IMPA2 $2^{-/-}$mice following administration of 100 or $200 \mathrm{mg} / \mathrm{kg}$ pilocarpine. To further study the possibility of lithium augmentation to reveal pilocarpine sensitivity of the IMPA2 $2^{-1-}$ mice, we pretreated IMPA2 $2^{-1-}$ and $I M P A 2^{+/+}$mice with 3 or $6 \mathrm{meq} / \mathrm{kg}$ lithium. No limbic seizures following administration of $100 \mathrm{mg} / \mathrm{kg}$ pilocarpine were obtained in any group of mice.

Injection of $100 \mathrm{mg} / \mathrm{kg}$ pilocarpine has previously been shown to induce limbic seizures in mice pretreated with $10 \mathrm{meq} / \mathrm{kg}$ lithium (Bersudsky et al, 1994). As a positive control, $100 \mathrm{mg} / \mathrm{kg}$ pilocarpine following $10 \mathrm{meq} / \mathrm{kg}$ lithium were injected to IMPA2 $2^{-/-}$and IMPA2 ${ }^{+/+}$mice. As expected, limbic seizures in both groups were observed with no difference in latency to clonus and seizure score between the two groups of mice.

Table $4 \mathrm{ACTH}$ and CORT Levels in $1 \mathrm{MPA} 2^{+/+}$and $I M P A 2^{-1-}$ Mice in Basal Conditions and after Forced Swim Stress

\begin{tabular}{|c|c|c|c|c|}
\hline Genotype & Gender & Stress & ACTH $(\mathrm{pg} / \mathrm{ml})$ & CORT (ng/ml) \\
\hline $\mathrm{MPA2}^{+/+}$ & Male & No & $348.78 \pm 25.86$ & $41.18 \pm 9.99$ \\
\hline IMPA2 $2^{-1-}$ & Male & No & $314.18 \pm 27.98$ & $34.80 \pm 9.29$ \\
\hline$I M P A 2^{+/+}$ & Female & No & $215.24 \pm 20.45 *$ & $69.93 \pm 20.74$ \\
\hline IMPA2 ${ }^{-1-}$ & Female & No & $|65.20 \pm 22.7| *$ & $51.28 \pm|3.7|$ \\
\hline $1 M P A 2^{+/+}$ & Female & Forced swim stress & $410 \pm 52.5$ & $569.7 \pm 23.5$ \\
\hline
\end{tabular}

Results are represented as means \pm SEM.

Asterisk indicates significant difference compared to male littermates. 


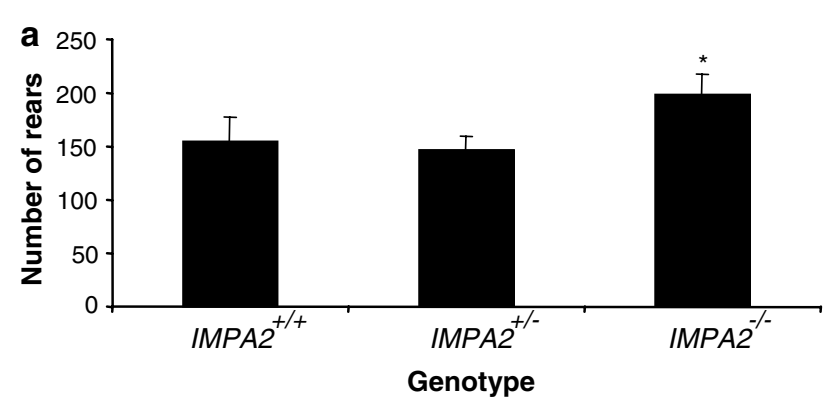

Table 5 Lethality of IMPA2 $2^{+/+}$and IMPA2 $2^{-1-}$ Mice $24 \mathrm{~h}$ and 5 Days after Injection With $\mathrm{LiCl}$

\begin{tabular}{lccc}
\hline & IMPA2 $^{\text {+/+ }}$ & IMPA2 $^{-1-}$ & P-value \\
\hline $24 \mathrm{~h}$ & $19 / 19$ & $14 / 17$ & 0.095 \\
5 days & - & $16 / 17$ & 0.472 \\
\hline
\end{tabular}

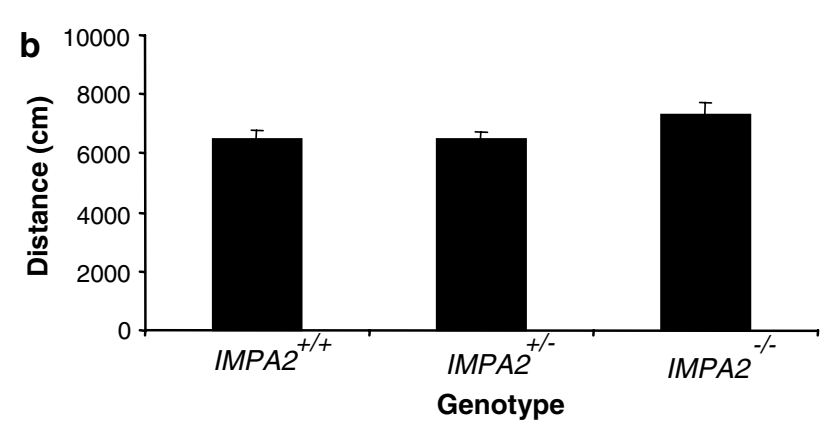

C
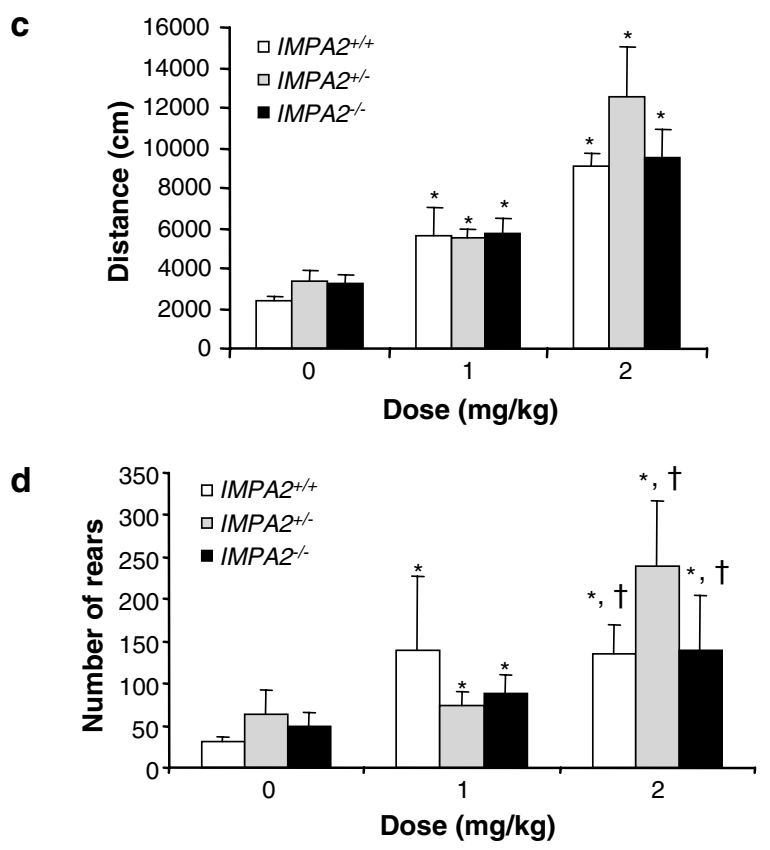

Figure 3 Behavioral response to $d$-amphetamine in $1 \mathrm{MPA}^{+/+}, \mathrm{IMPA}^{+/-}$, and IMPA2 $2^{-1-}$ mice. (a) Mice were placed in an automated open field for an initial period of I h before injection with saline or $d$-amphetamine (I or $2 \mathrm{mg} / \mathrm{kg}$ ). Before drug administration, rearing was significantly increased in IMPA2 ${ }^{-1-}$ mice. Asterisk indicates significant difference $(p=0.04) \mathrm{com}-$ pared to IMPA2 $2^{+/-}$mice. (b) In baseline conditions, the total distance traveled was not different between the three genotypes tested. (c) Locomotor behavior was quantified for a period of $2 \mathrm{~h}$ after injection. Amphetamine treatment resulted in a significant increase in locomotor activity. No genotype or genotype $\times$ drug interaction effect on the total distance traveled was observed. The asterisks shows main effects of amphetamine treatment compared to saline-treated animals. (d) Amphetamine treatment resulted in a significant increase in the number of rearings. No genotype effect or a genotype $x$ treatment interaction was observed. Asterisk and † represent a significant difference compared to animals treated with 0 and $1 \mathrm{mg} / \mathrm{kg}$, respectively. Results are represented as means \pm SEM.

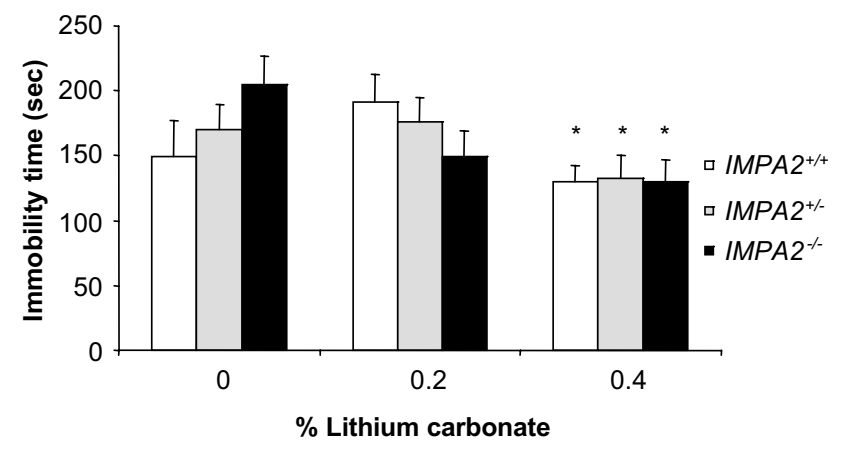

Figure 4 Effect of chronic lithium treatment on immobility time in $I M P A 2^{+1+}, I M P A 2^{+/-}$, and IMPA2 $2^{-1-}$ mice. Results are means \pm SEM. *Effect of lithium treatment compared to control group. There was no effect of genotype and no genotype $\times$ drug interaction.

$L D_{50}$ of lithium. Lethality of IMPA2 $2^{+/+}$and IMPA2 $2^{-/-}$ mice $24 \mathrm{~h}$ and 5 days following injection (i.p.) of isotonic lithium solution $(20 \mathrm{meq} / \mathrm{kg})$ is summarized in Table 5 . $I M P A 2^{-1-}$ mice did not show a different sensitivity to LiClinduced lethality compared to IMPA2 ${ }^{+/+}$mice.

Effect of chronic lithium treatment on the forced swim test. IMPA2 $2^{+/+}, I M P A 2^{+/-}$, and IMPA2 $2^{-/-}$mice were subjected to forced swim testing following chronic lithium treatment. A two-way ANOVA revealed a significant effect of treatment $\left(\mathrm{F}_{(2,112)}=5.377, p=0.006\right)$ on immobility time (Figure 4). Post hoc analysis indicated that animals treated with $0.4 \%$ lithium carbonate showed reduced immobility time in the forced swim test $(p=0.012)$ compared to mice treated with control chow. No effect of genotype $\left(\mathrm{F}_{(2,112)}=0.0429, \quad p=0.958\right) \quad$ or a genotype $\times$ treatment interaction was observed $\left(\mathrm{F}_{(4,112)}=1.351, p=0.256\right)$.

\section{DISCUSSION}

Inositol is a cyclic polyol that forms the backbone of important intracellular signaling molecules. Therefore, profound effects on the cell can be expected if one interferes with inositol formation. Interestingly, lithium, valproic acid, and carbamazepine are three drugs with mood-stabilizing properties that decrease myo-inositol levels (for a review, see Harwood, 2005). Based on these observations, inositol depletion was proposed as a therapeutic mechanism in the treatment of bipolar disorder (Berridge et al, 1989). IMPase is a key enzyme in establishing this depletion in the case of lithium. The inositol depletion hypothesis has been the subject of much debate and current data are neither convincing in favor of, nor eliminate the possibility of this 
hypothesis. In the present work, we phenotyped IMPA2 $2^{-1-}$ mice molecularly and behaviorally to better understand the contribution of IMPA2 to brain IMPase activity and inositol levels and the possible involvement of this gene in affective disorders.

IMPA $2^{-/-}$mice grow and reproduce normally, suggesting that their somatic and sexual development is normal. The absence of major developmental abnormalities in these mice also suggests that the IMPA2 gene does not play an essential role during development.

Possible involvement of IMPase in complex behaviors related to affective disorders was assessed by monitoring the behavior of IMPA2 $2^{-/-}$mice in the forced swim test and the tail suspension test modeling depression and in the elevated zero-maze and open field test modeling anxiety. Male IMPA2 $2^{-1-}$ mice did not show aberrant behavior in the forced swim test. In contrast, female IMPA2 $2^{-/-}$mice showed a small $(9.5 \%)$ but significant decrease in immobility time in the forced swim test. A significant increase in the total time in motion and the total distance traveled in the open field test was also observed in female IMPA2 $2^{-/-}$ mice while these parameters were unaltered in male IMPA2 $2^{-/-}$mice. Therefore, the aberrant behavior of female $I M P A 2^{-/-}$mice in the forced swim test most likely reflects an increased locomotor behavior rather than an antidepressant phenotype. Interestingly, a different depressive phenotype in male $v s$ female mice has also been shown in 5HT knockout mice (Jones and Lucki, 2005). There was no difference between male and female IMPA2 $2^{-1-}$ and $I M P A 2^{+/+}$mice in the tail suspension test, overall suggesting no effect of the deletion of the IMPA2 gene on the depression-like behavior.

A trend towards an increased number of rears in the open field was observed in male and female IMPA2 $2^{-1-}$ mice monitored for $30 \mathrm{~min}$. This trend reached significance in a third mouse panel monitored for $60 \mathrm{~min}$ (prior to amphetamine administration), suggesting an increased exploratory behavior. Kofman et al (1991) reported reduced rearing in lithium-treated mice, an effect reversed by inositol administration, and enhanced rearing following dietary inositol load (Kofman et al, 1998). Thus, it may have been expected that IMPA2 $2^{-/-}$mice would show reduced rearing as a lithium-like effect. Counterintuitively, an enhancement was observed. Interestingly, it has recently been shown that mice treated with the antidepressant fluoxetine at an early postnatal age (pd 4-pd 20) demonstrate depressive- and anxiety-like behaviors at adulthood in contrast with the antidepressant and anxiolytic effects of SSRIs when administered at an adult age (Ansorge et al, 2004). In parallel, it may be that lifelong reduction in IMPA2 levels affects rearing differently than chronic lithium treatment of adult mice.

In the anxiety-related open field test, the relative time spent in the center was significantly higher in male but not female IMPA2 $2^{-/-}$mice. This finding, together with the fact that IMPA2 $2^{-/-}$mice showed increased rearing in the open field test, could indicate that IMPA2 $2^{-1-}$ exhibit a lower anxiety level compared to control mice. In contrast, no anxiolytic phenotype was observed in the elevated zeromaze test in either gender of the $\mathrm{KO}$ mice. Interestingly, similar contrasting findings have been described by Montkowski et al (1997) who compared different mouse strains in the open field test and elevated plus maze. They suggested that as both tests measure rodents' innate fear of a novel environment, the contrasting findings support the notion that the open field is a stronger fear-inducing stimulus than the plus maze. However, detailed analysis of rearing and of relative time spent in the center of the open field over $5 \mathrm{~min}$ time-bins in mouse panel 1 indicated rearing was only significantly increased in $I M P A 2^{-/-}$mice $10 \mathrm{~min}$ after introduction to the open field and this difference disappeared after $15 \mathrm{~min}$ (data not shown). Moreover, although an overall significant difference was seen between IMPA2 $2^{-/-}$and wild-type mice in the relative time spent in the center, no difference was seen when data were analyzed in 5 min time-bins (data not shown), that is, for neither parameter a genotype effect was seen during the first $10 \mathrm{~min}$ of the test session. This would suggest that $I M P A 2^{-/-}$mice show increased exploratory behavior rather than an anxiolytic phenotype.

CORT and ACTH levels were measured in male and female IMPA2 $2^{+/+}$and IMPA2 $2^{-/-}$mice. No significant effect of genotype or a genotype $\times$ gender interaction was seen on CORT and ACTH levels. ACTH levels were significantly different between male and female mice, whereas CORT levels were not different between both genders. It should be noted that gender differences in HPA-axis activity have been well demonstrated by others (eg Timpl et al, 1998). In a subsequent experiment, it was shown that female IMPA2 $2^{-1-}$ mice did not show altered stress-hormone levels compared to female IMPA2 $2^{-1-}$ mice after forced swim stress, thereby suggesting that IMPA2 is not involved in modulation of the HPA axis.

Amphetamine is an indirect dopamine-receptor agonist as it elevates extracellular dopamine levels in mouse striatum. Hyperlocomotion in the open field test after $d$ amphetamine administration is considered to be an animal model for mania (Einat and Belmaker, 2001), and lithium salts are reported to antagonize this behavior (Einat and Belmaker, 2001). Amphetamine clearly induced hyperlocomotion as measured by a significant increase in the distance traveled, but no effect of genotype or a genotype $\times$ drug interaction was observed, indicating that IMPA2 $2^{-/-}$mice do not differently respond to amphetamine-induced manic-like behavior.

To study the possible involvement of the IMPA2 gene in the molecular mechanism of lithium's inhibitory effect on IMPase, we used the behavioral paradigm of lithiumpilocarpine seizures. It has been suggested that brain inositol depletion due to IMPase inhibition is critical to the development of lithium-pilocarpine-induced seizures (Kofman and Belmaker, 1993). We therefore hypothesized that IMPA2 $2^{-/-}$mice would present a lithium-like effect in this paradigm. No limbic seizures were observed in $I M P A 2^{-/-}$mice following subconvulsive pilocarpine doses. These data suggest that the IMPA2 gene does not significantly contribute to brain IMPase activity and therefore knocking it out is not enough to mimic this behavioral effect of lithium. The fact that we did not find inositol depletion or reduced IMPase activity in the frontal cortex and in the hippocampus of IMPA2 $2^{-1-}$ compared with IMPA $2^{+/+}$mice is consistent with this conclusion. Chronic lithium treatment resulted in a significant reduction in immobility time but no genotype or genotype $\times$ treatment 
interaction was seen, indicating lack of augmentation effect of IMPA2 knockout on the antidepressant effect of lithium in the forced swim test (O'Brien et al, 2004). It should be noted that the reduction in immobility time was only observed in the animals treated with food containing $0.4 \%$ lithium. This treatment regime results in lithium plasma levels that are higher than the therapeutic range in humans (data not shown). Furthermore, mice from the $0.4 \%$ group showed a reduction in body weight (data not shown), which might interfere with their behavior. Therefore, the reduction in immobility time should be interpreted cautiously.

Among tissues studied, IMPA2 expression is highest in kidney. We therefore studied the effect of $I M P A 2^{-1-}$ on IMPase activity and inositol levels in this tissue. We did find a gene-dose effect on kidney inositol levels in the IMPA2 $2^{-/-}$ mice raising the possibility that the IMPA2 gene is involved in renal side effects of lithium treatment. Bersudsky et al (1992) have previously reported that lithium-treated rats that drank inositol solution developed polydipsia much slower than rats drinking mannitol solution.

Altogether our results indicate that deletion of the IMPA2 gene did not resemble the pharmacological effects of lithium. Gene targeting to create null mutations in mice is a powerful tool to study complex phenotypes and assessing how genes influence biological functions in vivo. Yet, if a KO mouse does not exhibit a phenotypical change it maybe due to compensatory effects of other genes. However, no difference in brain or liver IMPA1 expression levels was found between IMPA2 $2^{-/-}$and IMPA2 $2^{+/+}$mice ruling out the possibility that the lack of phenotypical changes in $I M P A 2^{-1-}$ mice results from a compensatory upregulation of the IMPA1 gene. In this context, it is also not conceivable that the $24 \%$ increase in hippocampal IMPase activity in the $I M P A 2^{-1-}$ mice is responsible for the lack of phenotypical changes as our assay measures the $V_{\max }$ of the enzyme, whereas in vivo a much lower enzyme rate is physiologically sufficient.

It is noteworthy that the effectiveness of inositol depletion will also depend on influx of inositol from exogenous sources. In the brain, there are two myo-inositol transporters. SMIT (sodium/myo-inositol transporter) is dependent on $\mathrm{Na}^{+}$and inhibited at reduced $\mathrm{pH}$ (Hager et al, 1995). The second transporter is HMIT $\left(\mathrm{H}^{+} /\right.$myo-inositol transporter), which is activated as the $\mathrm{pH}$ lowers. After depolarization and activation of protein kinase $\mathrm{C}$ (PKC), HMIT is translocated to the plasma membrane at growth cones, leading to an increased myo-inositol uptake (Uldry et al, 2004). Interestingly, gene expression profiling indicated that $\mathrm{PKC} \varepsilon$ and $\mathrm{PKC} l$ are both upregulated in hippocampus of IMPA2 ${ }^{-/-}$mice (data not shown). This upregulation may lead to an increased exogenous inositol uptake via HMIT, thereby compensating for the inositol depletion. Alternatively, absence of a lithium-like phenotype in $I M P A 2^{-/-}$mice may point to functional redundancy of IMPA2, potentially provided by IMPA1 (Cryns et al, 2005). This is supported by the fact that the expression of IMPA1 is several fold higher than that of IMPA2 in mice and in human frontal cortex (Agam et al, 2002).

In conclusion, molecular, behavioral, and pharmacologic analysis of the IMPA2 $2^{-1-}$ mouse indicates that deleting the IMPA2 gene does not mimic the effects of lithium treatment. Compensatory mechanisms and/or functional redundancy may be responsible for the absence of depression- or mania-related phenotypes. To exhibit lithium-like behavioral and molecular effects, IMPA1 or both IMPase genes may have to be knocked out. Yet, even in $S M I T^{-1-}$ mice with the most severe inositol deficiency ever recorded in mammals, there is no significant loss of phosphatidylinositol (Berry et al, 2004).

\section{ACKNOWLEDGEMENTS}

We gratefully acknowledge Ms Ilse Leenaerts, Dr Jos Prickaerts, Dr Adriaan Bouwknecht, and Ms Carolien Janssen for their experimental/analytical work contribution.

\section{REFERENCES}

Agam G, Shamir A, Shaltiel G, Greenberg ML (2002). Myo-inositol1-phosphate (MIP) synthase: a possible new target for antibipolar drugs. Bipolar Disord 4: 15-20.

Ansorge MS, Zhou M, Lira A, Hen R, Gingrich JA (2004). Early-life blockade of the 5-HT transporter alters emotional behavior in adult mice. Science 306: 879-881.

Atack JR, Broughton HB, Pollack SJ (1995). Inositol monophosphatase - a putative target for $\mathrm{Li}+$ in the treatment of bipolar disorder. Trends Neurosci 18: 343-349.

Berrettini WH, Ferraro TN, Goldin LR, Weeks DE, DeteraWadleigh S, Nurnberger JI et al (1994). Chromosome 18 DNA markers and manic-depressive illness: evidence for a susceptibility gene. Proc Natl Acad Sci USA 91: 5918-5921.

Berridge MJ, Downes CP, Hanley MR (1989). Neural and developmental actions of lithium: a unifying hypothesis. Cell 59: 411-419.

Berry GT, Buccafusca R, Greer JJ, Eccleston E (2004). Phosphoinositide deficiency due to inositol depletion is not a mechanism of lithium action in brain. Mol Genet Metab 82: 87-92.

Bersudsky Y, Mahler O, Kofman O, Belmaker RH (1994). Species differences in susceptibility to Li-pilocarpine seizures. Eur Neuropsychopharmacol 4: 429-430.

Bersudsky Y, Vinnitsky I, Ghelber D, Kofman O, Kaplan Z, Belmaker RH (1993). Mechanism of lithium lethality in rats. $J$ Psych Res 27: 415-422.

Bersudsky Y, Vinnitsky I, Grisaru N, Yaroslavsky U, Gheorghiu S, Ivgi D et al (1992). The effect of inositol on litihum-inducedpolyuria-polydipsia in rats and human. Hum Psychopharmacol 7: 403-407.

Cryns K, Daneels G, Goris I, Peeters PJ, Van Craenendonck H, Steckler $\mathrm{T}$ et al (2005). Phenotypic characterization of the myo-inositol monophosphatase 1 (IMPA1)-deficient mice. 'Neuroscience Meeting 2005. Washington, DC, pp No. 559.1.

Einat H, Belmaker RH (2001). The effects of inositol treatment in animal models of psychiatric disorders. J Affect Disord 62: 113-121.

Goodwin FK, Jamison KR (1990). Manic-Depressive Illness. Oxford University Press: New York.

Hager K, Hazama A, Kwon HM, Loo DD, Handler JS, Wright EM (1995). Kinetics and specificity of the renal Na+/myo-inositol cotransporter expressed in Xenopus oocytes. J Membr Biol 143: 103-113.

Harwood AJ (2005). Lithium and bipolar mood disorder: the inositol-depletion hypothesis revisited. Mol Psychiatry 10: 117-126.

Honchar MP, Olney JW, Sherman WR (1983). Systemic cholinergic agents induce seizures and brain damage in lithium-treated rats. Science 220: 323-325.

Jones MD, Lucki I (2005). Sex differences in the regulation of serotonergic transmission and behavior in 5-HT receptor knockout mice. Neuropsychopharmacology 30: 1039-1047. 
Jope RS (1999). A bimodal model of the mechanism of action of lithium. Mol Psychiatry 4: 21-25.

Kofman O, Agam G, Shapiro J, Spencer A (1998). Chronic dietary inositol enhances locomotor activity and brain inositol levels in rats. Psychopharmacology (Berl) 139: 239-242.

Kofman O, Belmaker RH (1993). Ziskind-Somerfeld Research Award 1993. Biochemical, behavioral, and clinical studies of the role of inositol in lithium treatment and depression. Biol Psychiatry 34: 839-852.

Kofman O, Belmaker RH, Grisaru N, Alpert C, Fuchs I, Katz V et al (1991). Myo-inositol attenuates two specific behavioral effects of acute lithium in rats. Psychopharmocol Bull 27: 185-190.

Kofman O, Sherman WR, Katz V, Belmaker RH (1993). Restoration of brain myo-inositol levels in rats increases latency to lithiumpilocarpine seizures. Psychopharmacology (Berl) 110: 229-234.

Montkowski A, Poettig M, Mederer A, Holsboer F (1997). Behavioural performance in three substrains of mouse strain 129. Brain Res 762: 12-18.

Motulsky H (1995). Intuitive Biostatistics. Oxford University Press: New-York. pp 299-300.

O'Brien WT, Harper AD, Jove F, Woodgett JR, Maretto S, Piccolo S et al (2004). Glycogen synthase kinase-3beta haploinsufficiency mimics the behavioral and molecular effects of lithium. $J$ Neurosci 24: 6791-6798.

Patel S, Meldrum BS, Fine A (1988). Susceptibility to pilocarpineinduced seizures in rats increases with age. Behav Brain Res 31: 165-167.

Quiroz JA, Gould TD, Manji HK. (2004). Molecular effects of lithium. Mol Interv 4: 259-272.

Rojas K, Liang L, Johnson EI, Berraettini WH, Overhauser J (2000). Identification of candidate genes for psychiatric disorders on 18p11. Mol Psychiatry 5: 389-395.

Shaltiel G, Shamir A, Shapiro J, Ding D, Dalton E, Bialer M et al (2004). Valproate decreases inositol biosynthesis. Biol Psychiatry 56: $868-874$

Shapiro J, Belmaker RH, Biegon A, Seker A, Agam G (2000). Scylloinositol in post-mortem brain of bipolar, unipolar and schizophrenic patients. J Neural Transm 107: 603-607.
Sjoholt G, Ebstein RP, Lie RT, Berle JO, Mallet J, Deleuze JF et al (2004). Examination of IMPA1 and IMPA2 genes in manic-depressive patients: association between IMPA2 promoter polymorphisms and bipolar disorder. Mol Psychiatry 9: 621-629.

Sjoholt G, Gulbrandsen AK, Lovlie R, Berle J, Molven A, Steen VM (2000). A human myo-inositol monophosphatase gene (IMPA2) localized in a putative susceptibility region for bipolar disorder on chromosome 18p11.2: genomic structure and polymorphism screening in manic-depressive patients. Mol Psychiatry 5: 172-180.

Sjoholt G, Molven A, Lovlie R, Wilcox A, Sikela JM, Steen VM (1997). Genomic structure and chromosomal localization of a human myo-inositol monophosphatase gene (IMPA). Genomics 45: $113-122$.

Timpl P, Spanagel R, Sillaber I, Kresse A, Reul JMH, Stalla GK et al (1998). Impaired stress response and reduced anxiety in mice lacking a functional corticotropin-releasing hormone receptor 1. Nat Genet 19: 162-166.

Uldry M, Steiner P, Zurich MG, Beguin P, Hirling H, Dolci W et al (2004). Regulated exocytosis of an $\mathrm{H}+$ /myo-inositol symporter at synapses and growth cones. EMBO J 23: 531-540 (Epub 2004 Jan 29).

Williams RS, Cheng L, Mudge AW, Harwood AJ (2002). A common mechanism of action for three mood-stabilizing drugs. Nature 417: 292-295.

Yoon IS, Li PP, Siu KP, Kennedy JL, Cooke RG, Parikh SV et al (2001). Altered IMPA2 gene expression and calcium homeostasis in bipolar disorder. Mol Psychiatry 6: 678-683.

Yoshikawa T, Padigaru M, Karkera JD, Sharma M, Berrettini WH, Esterling LE et al (2000). Genomic structure and novel variants of myo-inositol monophosphatase 2 (IMPA2). Mol Psychiatry 5: $165-171$.

Yoshikawa T, Turner G, Esterling LE, Sanders AR, DeteraWadleigh SD (1997). A novel human myo-inositol monophosphatase gene, IMP.18p, maps to a susceptibility region for bipolar disorder. Mol Psychiatry 2: 393-397.

Zambrowicz BP, Friedrich GA (1998). Comprehensive mammalian genetics: history and future prospects of gene trapping in the mouse. Int J Dev Biol 42: 1025-1036. 